Article

\title{
Effect of $\mathrm{AlF}_{3}$ on the Density and Elastic Properties of Zinc Tellurite Glass Systems
}

\section{Haji Abdul Aziz Sidek *, Shaharuddin Rosmawati, Mohamed Kamari Halimah, Khamirul Amin Matori and Zainal Abidin Talib}

Glass Ceramic Composite Research Group (GCCG), Department of Physics, Faculty of Science, Universiti Putra Malaysia, 43400 UPM Serdang, Selangor, Malaysia;

E-Mails: rosma_shaha@yahoo.com (S.R.); halimah@science.upm.edu.my (M.K.H.); khamirul@science.upm.edu.my (K.A.M.); zainalat@science.upm.edu.my (Z.A.T.)

* Author to whom correspondence should be addressed; E-Mail: sidek@science.upm.edu.my; Tel.: +603-8946-6646; Fax: +603-8943-2508.

Received: 9 July 2012; in revised form: 20 July 2012 / Accepted: 27 July 2012 /

Published: 13 August 2012

\begin{abstract}
This paper presents the results of the physical and elastic properties of the ternary zinc oxyfluoro tellurite glass system. Systematic series of glasses $\left(\mathrm{AlF}_{3}\right)_{\mathrm{x}}(\mathrm{ZnO})_{\mathrm{y}}\left(\mathrm{TeO}_{2}\right)_{\mathrm{z}}$ with $\mathrm{x}=0-19, \mathrm{y}=0-20$ and $\mathrm{z}=80,85,90 \mathrm{~mol} \%$ were synthesized by the conventional rapid melt quenching technique. The composition dependence of the physical, mainly density and molar volume, and elastic properties is discussed in term of the $\mathrm{AlF}_{3}$ modifiers addition that are expected to produce quite substantial changes in their physical properties. The absence of any crystalline peaks in the X-ray diffraction (XRD) patterns of the present glass samples indicates the amorphous nature. The addition of $\mathrm{AlF}_{3}$ lowered the values of the densities in ternary oxyfluorotellurite glass systems. The longitudinal and transverse ultrasonic waves propagated in each glass sample were measured using a MBS8020 ultrasonic data acquisition system. All the velocity data were taken at $5 \mathrm{MHz}$ frequency and room temperature. The longitudinal modulus $(\mathrm{L})$, shear modulus $(\mathrm{G})$, Young's modulus $(\mathrm{E})$, bulk modulus $(\mathrm{K})$ and Poisson's ratio $(\sigma)$ are obtained from both velocities data and their respective density. Experimental data shows the density and elastic moduli of each $\mathrm{AlF}_{3}-\mathrm{ZnO}-\mathrm{TeO}_{2}$ series are found strongly depend upon the glass composition. The addition of $\mathrm{AlF}_{3}$ modifiers into the zinc tellurite causes substantial changes in their density, molar volume as well as their elastic properties.
\end{abstract}


Keywords: tellurite glass; zinc oxide; physical properties; elastic moduli

\section{Introduction}

Tellurite glasses are a relatively new vitreous material and appropriate candidates for new optical materials due to their excellent properties, such as high refractive index, high dielectric constants, a wide band infrared transmittance and substantial third order non-linear optical susceptibility. Their low melting temperatures and non-hygroscopic nature, which limit applications of phosphate and borate glasses, make them of much current interest [1,2]. It has been established that the basic structure of these tellurite glasses is a $\mathrm{TeO}_{4}$ trigonal bipyramid (tbp) with a lone pair of electrons in one of its equatorial sites [2].

The binary zinc oxide-tellurite glasses have been systematically studied where their densities increase with substitution of up to $40 \mathrm{~mol} \% \mathrm{ZnO}$ into the $\mathrm{TeO}_{2}$ network system. However, their molar volume decreases [3]. The addition of $\mathrm{ZnO}$ into the binary tellurite glass network reveals opposite behaviors to that of $\mathrm{ZnCl}_{2}$ [4], which are closely related to the structural changes.

The linear increase of the elastic modulus of $\mathrm{ZnCl}_{2}-\mathrm{TeO}_{2}$ glasses is associated with the force constants (f) for a constant mean ring size of each of the atoms involved [2]. The elastic moduli of $\mathrm{ZnCl}_{2}-\mathrm{TeO}_{2}$ glasses also increase due to cross-links for force constants of vitreous tellurite networks. The change in the force constant of $10 \%$ can be obtained by altering one Te-O bond into a Te-Cl bond and one $\mathrm{Zn}-\mathrm{Cl}$ bond into a $\mathrm{ZnO}$ bond. This is most likely the cause of the higher modulus and hence a reduction in the size of rings. However there are no coordination number changes in substituting $\mathrm{Cl}$ atoms with $\mathrm{O}$ atoms in $\mathrm{ZnCl}_{2}-\mathrm{TeO}_{2}$ glasses.

The sound velocities at a frequency of $10 \mathrm{MHz}$ and the elastic moduli for a $\mathrm{Na}_{2} \mathrm{O}-\mathrm{ZnO}-\mathrm{B}_{2} \mathrm{O}_{3}$ glass system as a function of $\mathrm{ZnO}$ concentration have been studied recently [5]. Both sound velocities and elastic moduli were found to increase with the addition of $\mathrm{ZnO}$ content. Poisson's ratio and Debye temperature were also found to increase with $\mathrm{ZnO}$ concentration. The results indicate that the $\mathrm{Zn}^{2+}$ ions are likely to occupy network forming positions in this glass system.

Meanwhile, both longitudinal and shear ultrasonic velocities, as well as their elastic moduli decreased with increasing $\mathrm{ZnF}_{2} \mathrm{~mol} \%$ content in the $\mathrm{TeO}_{2}-\mathrm{WO}_{3}-\mathrm{ZnF}_{2}$ glasses [6]. In this case, the addition of $\mathrm{ZnF}_{2}$ to the tellurite glass matrix weakens the structure by opening the network where the formation of non-bridging oxygen (NBO) is most influenced by the halide ions effect.

The objective the current work is to study the effect of $\mathrm{AlF}_{3}$ on the density and the elastic properties of zinc tellurite glass systems. The short-term significance of this work is to establish a baseline for the elastic properties of vitreous zinc tellurite with the addition of $\mathrm{AlF}_{3}$ into the glass network.

\section{Results and Discussion}

Figure 1 shows the X-ray diffraction (XRD) patterns of (the chemical compositions) and the corresponding scanning electron microscope (SEM) photographs of crystalline tellurite $\left(\mathrm{TeO}_{2}\right)$, zinc oxide $(\mathrm{ZnO})$ and aluminum fluoride $\left(\mathrm{AlF}_{3}\right)$ while the XRD patterns of zinc oxyfluoro tellurite glass samples obtained are shown in Figure 2. As depicted in Figure 2, all the zinc oxyfluorotellurite glass 
series were found to show no discrete or continuous sharp peaks but a broad halo at around $2 \Theta \cong 26^{\circ}-30^{\circ}$, which reflected the characteristic amorphous glass structure. This indicates the absence of a long-range atomic arrangement and the periodicity of the three dimensional network in the quenched material $[7,8]$.

Figure 1. (a) The X-ray diffraction (XRD) pattern; and (b) the corresponding scanning electron microscope (SEM) photographs of chemical powders of $\mathrm{TeO}_{2}$ (Technical Grade), $\mathrm{ZnO}(99.9 \%)$ and $\mathrm{AlF}_{3}(97.0 \%)$.

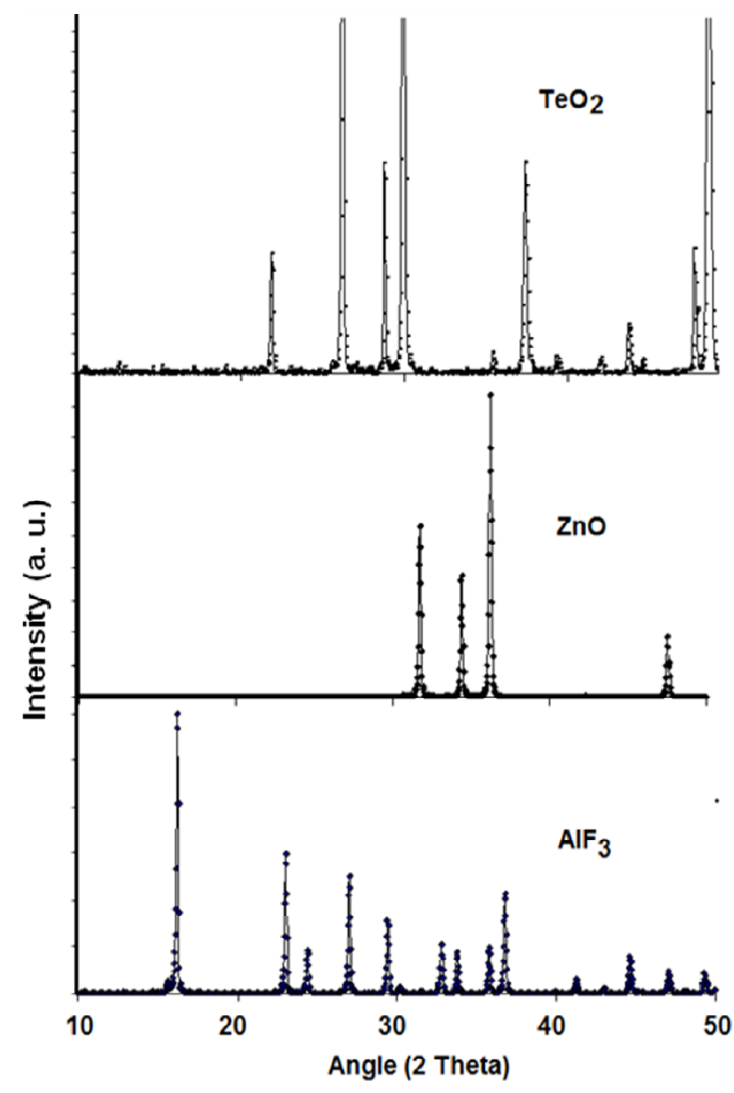

(a)

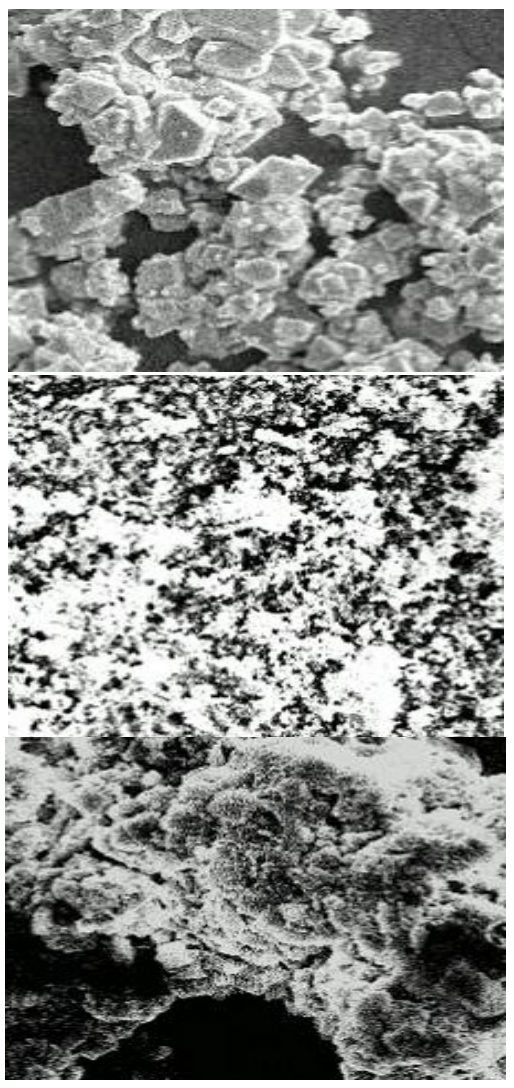

(b)

Figure 2. The XRD patterns of ternary zinc oxyfluoro tellurite glass series.

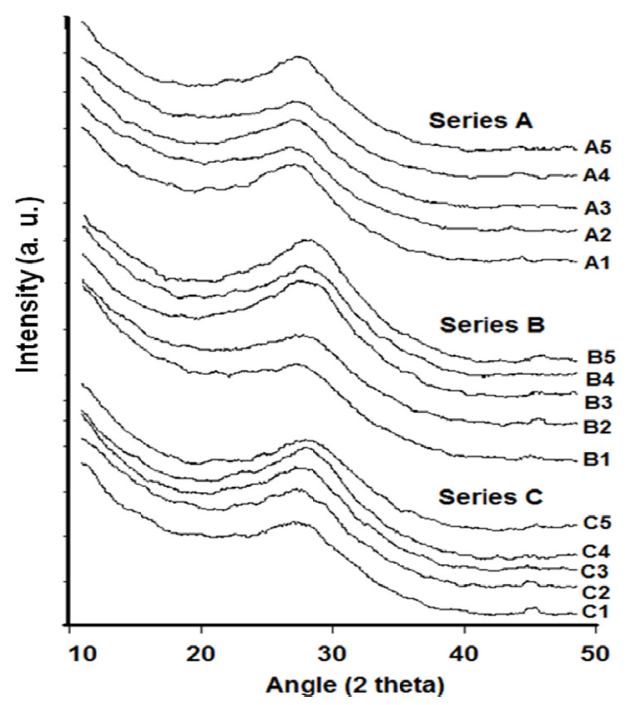


The densities and molar volumes for an $\mathrm{AlF}_{3}$ zinc tellurite glass system are presented in Table 1 and shown in Figure 3. The densities of $\mathrm{TeO}_{2}-\mathrm{ZnO}-\mathrm{AlF}_{3}$ samples decrease as the $\mathrm{AlF}_{3}$ was added to substitute the $\mathrm{ZnO}$ content. These results are in reasonable agreement with the statement of Mallawany's that the halogen substitution lowered the density [9]. Even the addition of $\mathrm{ZnCl}$ into the oxychloride glass system $\left(\mathrm{TeO}_{2}-\mathrm{ZnO}-\mathrm{ZnCl}\right)$ also lowered the densities of the $\mathrm{TeO}_{2}-\mathrm{ZnO}$ glass system [10].

Figure 3. Variation of density of $\mathrm{AlF}_{3}-\mathrm{ZnO}-\mathrm{TeO}_{2}$ glasses. The line is drawn to guide the eye.

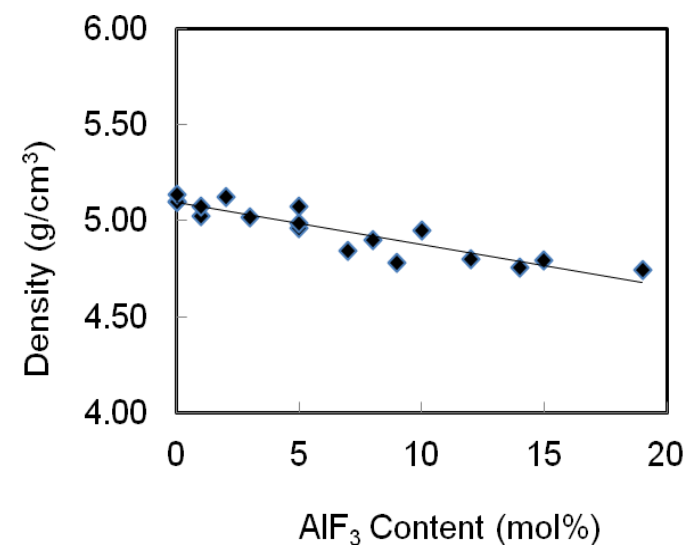

Table 1. Glass composition, density, molar volume, molecular weight, longitudinal and shear ultrasonic wave velocities of $\left(\mathrm{AlF}_{3}\right)_{\mathrm{x}}-(\mathrm{ZnO})_{\mathrm{y}}-\left(\mathrm{TeO}_{2}\right)_{\mathrm{z}}$ glasses. The pure $\mathrm{TeO}_{2}$ glass is included for comparison.

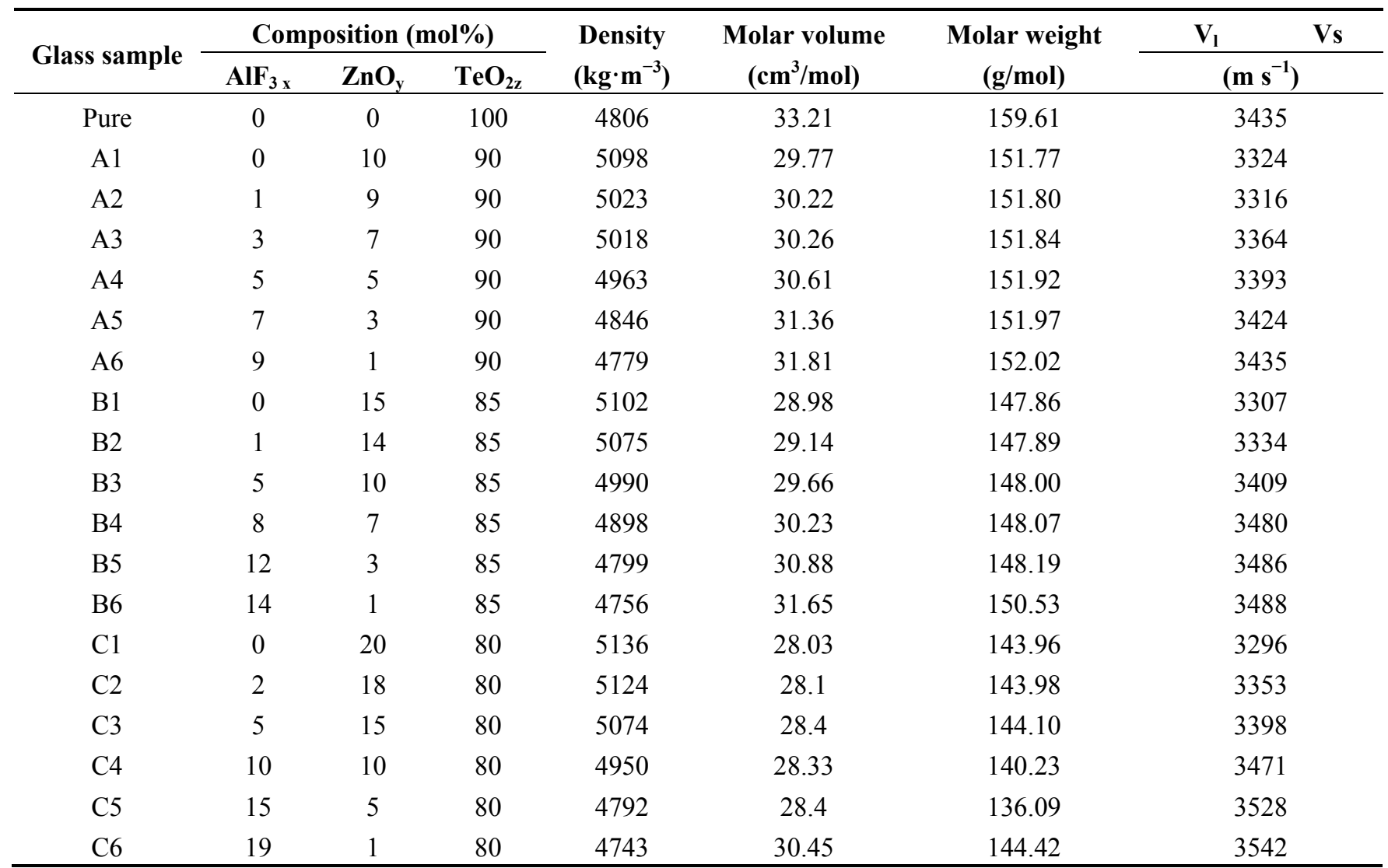


The densities decrease gradually with the addition of $\mathrm{AlF}_{3}$ content. In this case, as more $\mathrm{AlF}_{3}$ content are added into the zinc tellurite glass system, two $\mathrm{Zn}-\mathrm{F}$ single bonds will replace the $\mathrm{Zn}=\mathrm{O}$ double bonds, hence the structure of the glasses becomes loose, which results in a decrease in density. Fluorine plays an important role in the glass matrix; replacing the $\mathrm{O}^{2-}$ ions causes the compositional dependence of the density and molar volume [11]. The molecular weight of $\mathrm{TeO}_{2}$ is 159.599 which is greater than $\mathrm{AlF}_{3}$ (83.977) and $\mathrm{ZnO}$ (81.408). Whereas the atomic weight of individual constituent atom $\mathrm{Te}(127.6)>\mathrm{Zn}(65.39)>\mathrm{Al}(26.9815)>\mathrm{F}(18.998)>\mathrm{O}$ (15.9999), the atomic radius of each of the constituent atoms (in ppm) is $\mathrm{Al}(143)>\mathrm{Te}(140)>\mathrm{Zn}(134)>\mathrm{O}(66)>\mathrm{F}$ (64).

The slight increase in molar volumes is due to the rearrangement of the lattice and a decrease in the porosity of the glass. The increase in molar volumes for all series in ternary glass systems as shown Table 1 is related to a decrease in the bond length or inter-atomic spacing between the atoms. The radius of $\mathrm{Te}^{2+}(0.097 \mathrm{~nm})$ is much greater than that of $\mathrm{Zn}^{2+}(0.074 \mathrm{~nm})$ and since the radius of $\mathrm{Al}^{3+}$ is $0.0535 \mathrm{~nm}$ which also has a smaller radius than $\mathrm{Zn}^{2+}$ attributed to this situation.

The molar volumes for AlF3-ZnO-TeO2 results show slightly lower values than that of the pure tellurite glasses. The much higher reduction in the molar volume for the sample containing fluorine is attributed to the decrease in viscosity due to the breaking of the Te-O-Te bond to form two Te-F bonds, which increase the efficiency of the crystallization process [12].

The addition of $\mathrm{AlF}_{3}$ that consists of $\mathrm{Al}^{3+}$ and $\mathrm{F}$ will modify the glass structure by creating NBOs in the oxyflorotellurite glass system. The NBOs created were believed to alter the glass structure in a way that packing of the molecule becomes denser as more network modifier ions (in this case $\mathrm{Al}^{3+}$ ), attempt to occupy the interstices within the network.

The variation of both longitudinal and shear wave velocities that propagated in the present bulk samples depends on the structural change of the glass network. The longitudinal and shear ultrasonic velocities in ternary glass $\mathrm{TeO}_{2}-\mathrm{ZnO}-\mathrm{AlF}_{3}$ are depicted in Figure 4 and presented in Table 1 for different mole fractions of $\mathrm{AlF}_{3}$ content. It can be seen that in the glasses studied, both longitudinal and shear ultrasonic velocities increase when more $\mathrm{AlF}_{3}$ is added into the $\mathrm{ZnO}-\mathrm{TeO}_{2}$ glass system.

Figure 4. Variation of longitudinal and transverse wave velocities propagated in the $\mathrm{AlF}_{3}-\mathrm{ZnO}-\mathrm{TeO}_{2}$ glasses.

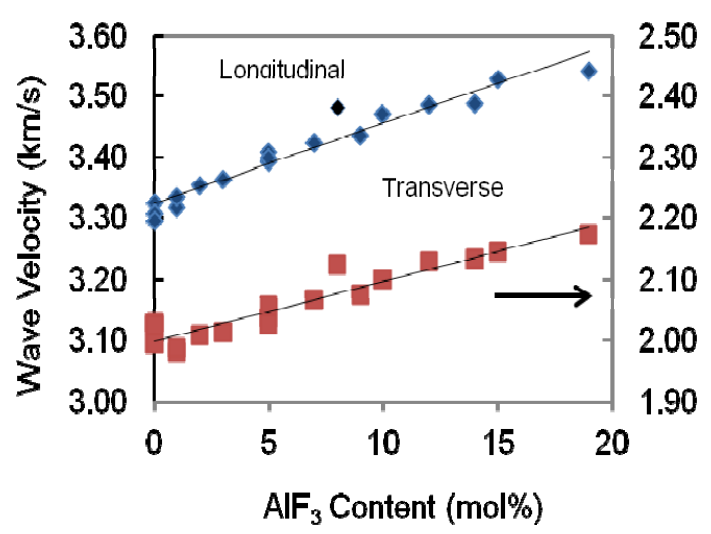

The percentage increase of velocity can be seen in Table 2 . The percentage of decrement in velocity increases with the increasing substitution of $\mathrm{AlF}_{3}$ content. Substituting more $\mathrm{AlF}_{3}$ content to $\mathrm{ZnO}$ content means that the difference between maximum velocity and minimum velocity is higher for both 
longitudinal and transverse or shear velocity. The addition of $\mathrm{AlF}_{3}$ content increase both wave velocities propagated in glass, and hence the elastic stiffness is also increased [13] as shown in Figure 5.

Table 2. The elastic moduli, Young's modulus (E), longitudinal modulus (L), shear modulus $(\mathrm{G})$, bulk modulus $(\mathrm{K})$ and Poisson's ratio $(\sigma)$ of ternary zinc tellurite glass.

\begin{tabular}{|c|c|c|c|c|c|c|c|}
\hline \multirow{2}{*}{ Glass sample } & \multicolumn{5}{|c|}{ Elastic moduli (GPa) } & \multirow{2}{*}{$\sigma$} & \multirow{2}{*}{$d=4 G / K$} \\
\hline & $\mathbf{L}$ & G & $\mathbf{E}$ & $\mathbf{K}$ & $\mathbf{H}$ & & \\
\hline Pure & 56.71 & 21.50 & 51.37 & 28.04 & 4.38 & 0.19 & 3.07 \\
\hline A1 & 56.33 & 21.01 & 50.53 & 28.32 & 4.17 & 0.20 & 2.97 \\
\hline $\mathrm{A} 2$ & 55.23 & 19.67 & 48.13 & 29.00 & 3.63 & 0.22 & 2.71 \\
\hline A3 & 56.79 & 20.33 & 49.66 & 29.67 & 3.78 & 0.22 & 2.74 \\
\hline A4 & 57.14 & 20.61 & 50.21 & 29.65 & 3.88 & 0.22 & 2.78 \\
\hline A5 & 56.81 & 20.72 & 50.27 & 29.18 & 3.97 & 0.21 & 2.84 \\
\hline A6 & 56.39 & 20.58 & 49.91 & 28.95 & 3.94 & 0.21 & 2.84 \\
\hline B1 & 55.80 & 20.90 & 50.18 & 27.93 & 4.17 & 0.20 & 2.99 \\
\hline B2 & 56.41 & 20.04 & 49.07 & 29.70 & 3.68 & 0.22 & 2.70 \\
\hline B3 & 57.99 & 21.11 & 51.25 & 29.84 & 4.03 & 0.21 & 2.83 \\
\hline B4 & 59.32 & 22.08 & 53.14 & 29.88 & 4.36 & 0.20 & 2.96 \\
\hline B5 & 58.32 & 21.75 & 52.32 & 29.32 & 4.31 & 0.20 & 2.97 \\
\hline B6 & 57.86 & 21.66 & 52.02 & 28.98 & 4.32 & 0.20 & 2.99 \\
\hline $\mathrm{C} 1$ & 55.80 & 20.44 & 49.51 & 28.54 & 3.94 & 0.21 & 2.86 \\
\hline $\mathrm{C} 2$ & 57.61 & 20.68 & 50.46 & 30.03 & 3.86 & 0.22 & 2.75 \\
\hline C3 & 58.59 & 20.83 & 50.99 & 30.82 & 3.83 & 0.22 & 2.70 \\
\hline $\mathrm{C} 4$ & 59.64 & 21.83 & 52.88 & 30.53 & 4.20 & 0.21 & 2.86 \\
\hline C5 & 59.64 & 22.05 & 53.21 & 30.25 & 4.31 & 0.21 & 2.92 \\
\hline C6 & 59.50 & 22.42 & 53.70 & 29.62 & 4.52 & 0.20 & 3.03 \\
\hline
\end{tabular}

Figure 5. Variation of elastic moduli in the $\mathrm{AlF}_{3}-\mathrm{ZnO}-\mathrm{TeO}_{2}$ glasses. The line is drawn to guide the eye.

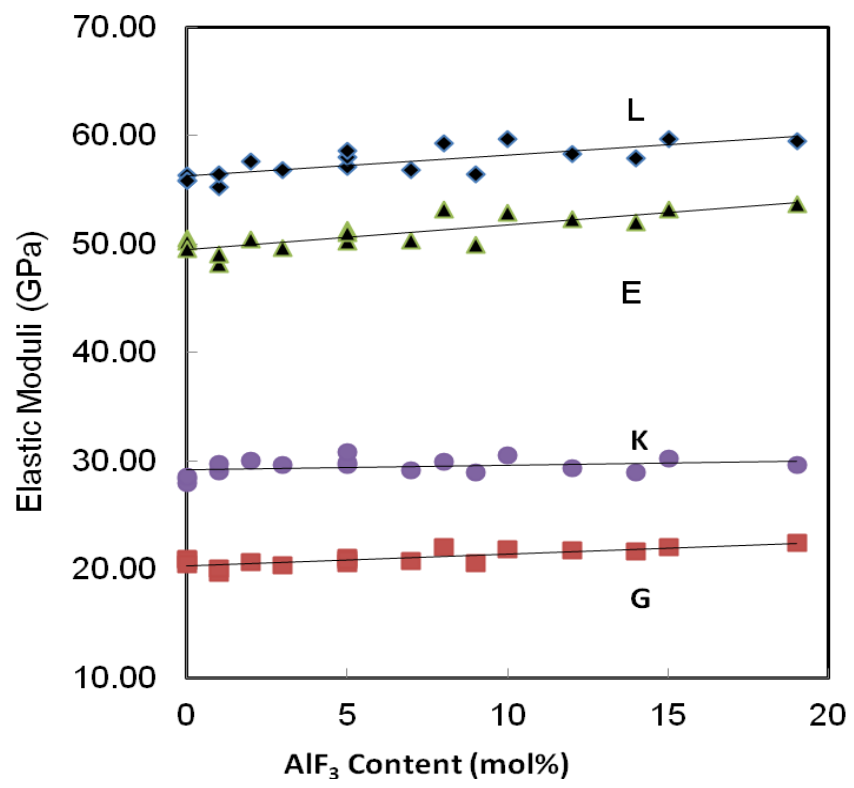


As a small quantity of $\mathrm{AlF}_{3}$ is added into the $\mathrm{TeO}_{2}-\mathrm{ZnO}$ glass network, a breaking of Te-O-Te takes place. The conversion of this linkage results in depolymerization of the network leading to the formation of $\mathrm{Te}-{ }_{\mathrm{ax}} \mathrm{O}_{\mathrm{eq}}-\mathrm{Te}$ bridges with the appearance of non-bridging oxygen (NBO) [14]. Therefore, the continuous breaking of Te-O-Te linkages with the addition of $\mathrm{AlF}_{3}$ content leads to the loose packing of the glass network and hence, a decrease in density (Figure 3). The observed results can be further substantiated by revealing the composition dependent on ultrasonic parameters.

It is inferred that a decrease in Te coordination number $(\mathrm{N})$ has resulted with the increase in the modifier content [15]. Further, a decrease in the coordination number results in a slight decrease in the mean Te-O bond length (R) [16]. Thus, it is inferred that the observed continuous increase in sound velocity in the present glasses is due to the change in coordination number with the substitution of $\mathrm{AlF}_{3}$.

The introduction of fluorine into $\mathrm{TeO}_{2}$-based glass system results in a reduction of Te-O-Te linkages due to a gradual transformation of trigonal bipyramid $\mathrm{TeO}_{4}$ (tbp) through $\mathrm{TeO}_{3+1}$ to trigonal pyramid $\mathrm{TeO}_{3}$, decreasing the connectivity of the tellurite glass former network [17]. This behavior is strengthened by the higher concentration of $\mathrm{F}^{-}$ions.

Elastic properties (longitudinal, transverse/shear, bulk and Young's moduli, Debye temperature and Poisson's ratio) of the present glasses have been determined from the measured ultrasonic velocities and densities. Table 2 gives experimental values of the elastic moduli: Young's modulus (E), longitudinal modulus (L), shear modulus $(\mathrm{G})$, bulk modulus $(\mathrm{K})$ and Poisson's ratio $(\sigma)$.

Similarly, all the elastic moduli show a monotonic increase as that of velocities, with an incremental increase of $\mathrm{AlF}_{3}$ into the $\mathrm{ZnO}-\mathrm{TeO}_{2}$ glass system for every series. For series $\mathrm{A}$, the Young's modulus increases from 48.13 to $49.91 \mathrm{GPa}$. This pattern is applied to the rest of the glass series. The additional increase of $\mathrm{AlF}_{3}$ results in higher network rigidity, which in turns results in an increase of the longitudinal and shear modulus. The increase in shear modulus, G, and bulk modulus, $\mathrm{K}$, is due to the stronger tendency of the change in the coordination number with increasing $\mathrm{AlF}_{3}$ content.

In ternary glasses both the degree of cross-linking and the relative proportions of different types of bonds may be changed with composition. The existence of $\mathrm{AlF}_{3}$ and the nature of $\mathrm{TeO}_{2}$ not only cause an increase in the elastic moduli, but also an increase in Poisson's ratio.

The values of Poisson's ratio of each glass series is tabulated in Table 2 and depicted in Figure 6. The Poisson's ratio shows a monotonic decrease as the $\mathrm{AlF}_{3}$ content increases for all glass series. For this glass series as an example, the Poisson's ratio increases from 0.223 to 0.213 . The values of the Poisson's ratio are of the order 0.2 which reveals a high cross-link density $[18,19]$. For all series of glass, the transformation of cross-linkage is negligibly small (changes of about 0.02), almost remaining constant. 
Figure 6. Poisson ratio and fractal dimensionality of $\mathrm{AlF}_{3}-\mathrm{ZnO}-\mathrm{TeO}_{2}$ glasses. The line is drawn to guide the eye.

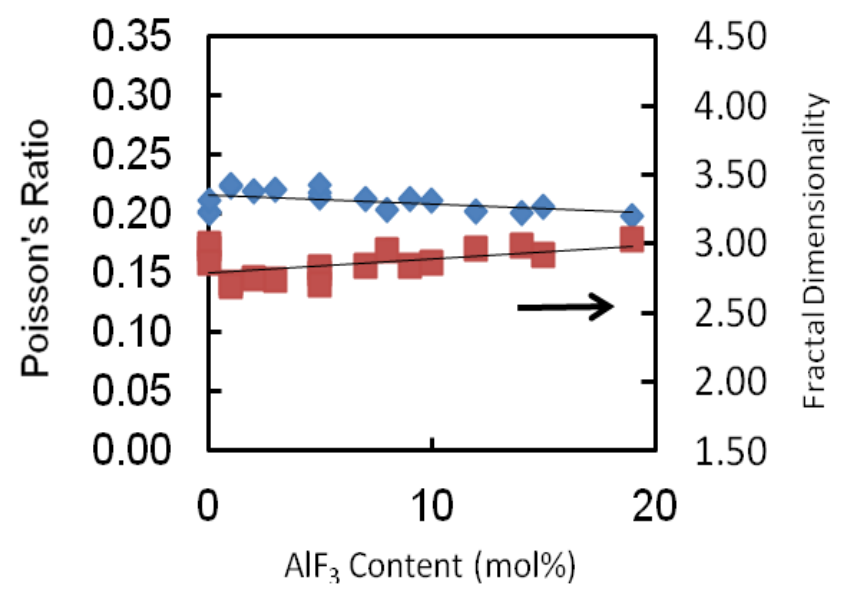

Table 2 collects the calculated values of microhardness. It can be seen that the microhardness of the studied glass samples, except for Series $\mathrm{A}$, increases with the addition of $\mathrm{AlF}_{3}$ content. As an example, for Series B, the microhardness increases from 4.17 to $4.32 \mathrm{GPa}$. The rest of glass samples show the same trend. It also indicates a strengthening in the glass structure which may be due to the introduction of stronger ionic bonds in the glass network [19,20].

The shear to bulk modulus ratio of oxyfluorotellurite glasses at room temperature is given in Table 2. The $G / K$ tends to decrease with increasing $\mathrm{AlF}_{3}$ content: consistent with the loss or weakening of cross-link between $\mathrm{TeO}_{2}$ chains. In this study, the fractal dimensionality, $(d)$ of these glasses ranges between 2.70 and 3.03. These suggest an intermediate connectivity in a three-dimensional disordered network, which implies a marked degree of cross-linkage between $\mathrm{TeO}_{2}$ chains, as would be anticipated for modifier cations whose valency is greater than unity, or increased branching of the network of $\mathrm{TeO}_{2}$ chains facilitated by an increase in the number of the end and branching units incorporated into the basic tellurite network.

All the current experimental data were analyzed using Microsoft Excel, by fitting regression curves, with the results of the regression coefficients presented in Table 3. The regression coefficients obtained from each curve is shown in Figures 3 to 6 . In Table 3, $\hat{Y}$ stands for the variables shown in the first column and $\hat{x}$ is the $\mathrm{ZnO}$ concentration. As can be seen in previous figures, for most of the variables, a linear curve $(\hat{Y}=\beta \hat{x}+\alpha)$ gives the best fit. Except for bulk modulus, Poisson's ratio and fractal dimensionality, $\mathrm{d}$, the $\mathrm{R}^{2}$ values lie between 0.527 to 0.9384 . 
Table 3. Linear regression analysis of the variables $(\hat{Y}=\beta \hat{x}+\alpha)$ for various properties of glass (density, $\rho$; longitudinal and shear ultrasonic velocities, $v_{l}, v_{s}$; elastic moduli, $L, G$, $K, E$; Poisson's ratio, $\sigma$; and fractal dimensionality, d).

\begin{tabular}{ccccc}
\hline Variables $(\hat{Y})$ & $\beta$ & $\alpha$ & $\mathbf{R}^{\mathbf{2}}$ & \% change \\
\hline Density, $\rho$ & -0.022 & 5.095 & 0.832 & -8.286 \\
Longitudinal Wave Velocity, $\mathrm{V}_{\mathrm{L}}$ & 0.013 & 3.323 & 0.938 & +7.464 \\
Transverse Wave, $\mathrm{V}_{\mathrm{S}}$ & 0.010 & 1.998 & 0.894 & +9.853 \\
Longitudinal Modulus, L & 0.189 & 56.294 & 0.578 & +7.984 \\
Shear Modulus, G & 0.1079 & 20.348 & 0.651 & +13.98 \\
Young's Modulus, E & 0.225 & 49.52 & 0.668 & +11.573 \\
Bulk Modulus, K & 0.046 & 29.163 & 0.120 & +10.347 \\
Poisson's Ratio, $\sigma$ & -0.001 & 0.217 & 0.275 & -9.998 \\
Fractal Dimensionality, d & 0.01 & 2.794 & 0.275 & +12.222 \\
\hline
\end{tabular}

The overall results from Table 3 show that the addition of $\mathrm{AlF}_{3}$ less than $19 \mathrm{~mol} \%$ into the zinc tellurite glass system causes a small effect (less than $12 \%$ ) on their physical properties as well as their elastic properties. However, it is difficult to completely separate the effects of increasing the $\mathrm{AlF}_{3}$ content and decreasing the $\mathrm{ZnO}$ content from the observed changes in glass properties.

\section{Experimental Procedure}

All glass samples were prepared by rapid melting quenching method. The ternary system consists of $\left(\mathrm{TeO}_{2}\right)_{\mathrm{x}}(\mathrm{ZnO})_{\mathrm{y}}\left(\mathrm{AlF}_{3}\right)_{\mathrm{z}}$ with $\mathrm{x}, \mathrm{y}$ and $\mathrm{z}$ being the mole fractions. The aluminum fluoride, $\mathrm{AlF}_{3}$, and zinc oxide, $\mathrm{ZnO}$, act as a glass modifier, while tellurite, $\mathrm{TeO}_{2}$ is a glass former. Table 1 shows the initial composition (mol\%): density, molar volume, molecular weight, longitudinal and shear ultrasonic wave velocities of $(\mathrm{AlF} 3)_{\mathrm{x}}-(\mathrm{ZnO})_{\mathrm{y}}-(\mathrm{TeO} 2)_{\mathrm{z}}$ glasses.

All the glass samples were prepared from commercial powders by mixing the specific weights of batches using tellurium (IV) oxide, $\mathrm{TeO}_{2}$ (Technical grade, Alfa Aesar, Ward Hill, MA, USA), zinc oxide, $\mathrm{ZnO}$ (99.99\%, Assay, Alfa Aesar, Ward Hill, MA, USA) and aluminum fluoride, $\mathrm{AlF}_{3}(97 \%$, Assay, Alfa Aesar, Ward Hill, MA, USA). Those starting materials were weighed using an electronic balance to obtain $20 \mathrm{~g}$ batches and mixed in the alumina crucible. Their initial glass compositions are presented in Table 1.

For the premelting process, a lidded alumina crucible which contained well mixed $20 \mathrm{~g}$ batches were then preheated in a preliminary furnace to $400{ }^{\circ} \mathrm{C}$ for 30 minutes. This process was carried out to evaporate water vapor and remove gases in the mixture and to allow the tellurite to decompose and react with other batch constituents before the melting process occurs [21]. The mixture of starting materials was then transferred into a second electric furnace and kept at $750{ }^{\circ} \mathrm{C}-800{ }^{\circ} \mathrm{C}$ for 1 hour. During the process, the crucible was slightly shaken using several times using a metal holder to ensure homogeneity and proper mixing. All the melting processes were performed using an electric furnace manufactured by Lindberg, Thermolyne and Bole.

After the melting process, each melt was rapidly quenched into a cylindrical stainless steel split mould which had been preheated to $400{ }^{\circ} \mathrm{C}$ for the glass casting process. The samples formed a glass rod of $2.0 \mathrm{~cm}$ height and $1.1 \mathrm{~cm}$ diameter. The reason to maintain the mould at this temperature is to 
relieve the mechanical stress in the glass sample. Then, the mould halves were released to prevent cracking [19]. Each glass sample was then annealed at $350^{\circ} \mathrm{C}$ for about an hour before the furnace was switched off. The glass samples were allowed to cool down in situ to room temperature for a day.

All the ternary glasses were free of bubbles, of exceptional quality and yellow in color. These samples were then cut into the required dimension using an Isomet Low Speed Saw machine (Buehler). The thickness of the glass sample was taken five times for each measurement. The glass samples were then ground using various grades of sand paper. The grades used were 150, 300, 600, $1000,1200,2000$ and 2700. This was done to obtain parallel, smooth and clear surfaces for each glass sample. There were three series of zinc oxyfluoride tellurite glass system, namely A, B and C, where each series consisted of six samples as shown in Table 1.

The densities $(\rho)$ of the glasses were determined by the Archimedes method with acetone as buoyant liquid [22]. All the glass samples' weights were measured with a digital balance $( \pm 0.0001 \mathrm{~g}$ accuracy). Their molar volume was calculated from the molecular weight $(M)$ and density $(\rho)$. The accuracy in the measurement of the density is $\pm 0.01 \mathrm{~g} \cdot \mathrm{cm}^{-3}$ and the relative error is $\pm 0.05 \%$.

The chemically estimated elemental composition values present in the glass samples with the Atomic Absorption Studies (Perkin-Elmer, Model 1372, Waltham, MA, USA) were found to be slightly smaller than the corresponding elemental nominal composition values (before the glass formation), which we considered to be due to evaporation losses and uncertainties in the chemical analysis.

All the glass samples were checked by X-ray diffraction for their amorphous nature using an X'Pert Pro Panalytical PW 3040 MPD X-ray powder diffractometer by employing $\mathrm{Cr}-\mathrm{K} a$ radiation.

For the measurements of ultrasonic velocity in each glass sample, the samples were shaped into a circular disc of $12 \mathrm{~mm}$ diameter and 10-12 mm thickness. The opposite faces of the disc shaped glass samples were highly polished using ultra fine lapping papers to achieve a good surface finish with plane parallelism having an accuracy of \pm 5 micron.

Ultrasonic velocity measurements were carried out at a frequency of $10 \mathrm{MHz}$ using $\mathrm{x}$-cut and y-cut quartz transducers. A pulse superposition technique was employed using Ultrasonic Data Acquisition System (MATEC 8020, Matec Instruments, Northborough, MA, USA) [23]. Burnt honey was used as a bonding material between the glass samples and transducers. By measuring the thickness of the sample $(d)$, longitudinal $\left(V_{1}\right)$ and transverse $\left(V_{\mathrm{t}}\right)$ wave velocities were calculated using the relationship, $V=2 d / t$ [24]. The absolute accuracy in the measurement of the velocity is $\pm 5 \mathrm{~ms}^{-1}$ and the relative error is $\pm 0.1 \%$. Glasses are isotropic and have only two independent elastic constants, $L$ and $G$, which can be obtained from their longitudinal and shear sound wave velocities and densities. The various elastic properties of the glasses were calculated using the following standard relations [25]:

$$
\begin{gathered}
\text { Longitudinal modulus } L=\rho V_{1}^{2} \\
\text { Shear modulus } G=\rho V_{\mathrm{s}}^{2} \\
\text { Bulk modulus } K=\rho\left(V_{l}^{2}-\frac{4}{3} V_{s}^{2}\right) \\
\text { Young's modulus } E=\frac{\rho V_{s}^{2}\left(3 V_{l}^{2}-4 V_{s}^{2}\right)}{V_{l}^{2}-V_{s}^{2}}
\end{gathered}
$$




$$
\text { Poisson's ratio } \sigma=\frac{\left(V_{l}^{2}-2 V_{s}^{2}\right)}{2\left(V_{l}^{2}-V_{s}^{2}\right)}
$$

Fractal dimensionality $d=4 G / K$

\section{Conclusions}

As a conclusion, a systematic series of zinc oxyfluoro tellurite glass systems have been successfully prepared and characterized in order to obtain their physical properties. Based on the results it showed that their densities decrease when glass modifier $\mathrm{AlF}_{3}$ is added into the zinc tellurite glass systems, while molar volumes increases. The decrease in density is also probably caused by a change in crosslink density and coordination number of $\mathrm{Te}^{2+}$ ions. The increase in the molar volume may be attributed to an increase in the bond length or interatomic spacing between the atoms. Ultrasonic properties such as velocity and elastic constant were affected considerably by glass composition. For the ternary oxyfluorotellurite glass system, it is obvious that the values of both velocities and other elastic moduli increase as more $\mathrm{AlF}_{3}$ is added into the zinc tellurite-based glass system. The observed continuous increase in sound velocity in the present glasses is due to the change in coordination number with the substitution of $\mathrm{AlF}_{3}$.

\section{Acknowledgements}

The financial support from Universiti Putra Malaysia (UPM), under the Research University Grant Scheme, vote No. 91748 is gratefully acknowledged.

\section{References}

1. Manning, S.; Heidepriem, H.E.; Monro, T.M. Ternary tellurite glasses for the fabrication of nonlinear optical fibres. Opt. Mater. Express 2012, 2, 140-152.

2. Kim, S.H.; Yoko, T.; Sakka, S. Linear and nonlinear optical properties of $\mathrm{TeO}_{2}$ glass. J. Am. Ceram. Soc. 1993, 76, 2486-2490.

3. El-Mallawany, R. Longitudinal elastic constants of tellurite glasses. J. Appl. Phys. 1993, 73, 4878-4880.

4. El-Mallawany, R.; Saunders, G.A. Elastic behaviour under pressure of the binary tellurite glasses $\mathrm{TeO}_{2}-\mathrm{ZnCl}_{2}$ and $\mathrm{TeO}_{2}-\mathrm{WO}_{3}$. J. Mater. Sci. Lett. 1987, 6, 443-446.

5. Gowda, V.V.C.; Anavekar, R.V. Elastic properties and spectroscopic studies of $\mathrm{Na}_{2} \mathrm{O}-\mathrm{ZnO}-\mathrm{B}_{2} \mathrm{O}_{3}$ glass system. Bull. Mater. Sci. 2004, 27, 199-205.

6. Yousef, E. Characterization of oxyfluoride tellurite glasses through thermal, optical and ultrasonic measurements. J. Phys. D Appl. Phys. 2005, 38, 3970-3975.

7. El-Mallawany, R. Review. Tellurite glasses part 1. Elastic properties. J. Mater. Chem. Phys. 1998, 53, 93-120.

8. El-Mallawany, R. Tellurite glasses: Part 2. Anelastic, phase separation, Debye temperature and thermal properties. Mater. Chem. Phys. 1999, 60, 103-131.

9. El-Mallawany, R. Ultrasonic attenuation of tellurite glasses. Mater. Chem. Phys. 1994, 37, 197-200. 
10. Sahar, M.R.; Nordin, N. Oxychloride glasses based on the $\mathrm{TeO}_{2}-\mathrm{ZnO}-\mathrm{ZnCl}_{2}$ system. J. Non-Cryst. Solids 1995, 184, 137-140.

11. Wang, G.; Dai, S.; Zhang, J.; Xu, S.; Hu, L.; Jiang, Z. Effect of $\mathrm{F}^{-}$ions on physical and spectroscopic properties of $\mathrm{Yb}^{3+}$-doped TeO2-based glasses. J. Luminesc. 2005, 113, 27-32.

12. Likitvanichkul, S.; Lacourse, W.C. Effect of fluorine content on crystallization of canasite glass-ceramics. J. Mater. Sci. 1995, 30, 6151-6155.

13. El-Mallawany, R.; El-Khoshkhany, N.; Afifi, H. Ultrasonic studies of $\left(\mathrm{TeO}_{2}\right)_{50}-\left(\mathrm{V}_{2} \mathrm{O}_{5}\right)_{50-\mathrm{x}}-\left(\mathrm{TiO}_{2}\right)_{\mathrm{x}}$ glasses. Mater. Chem. Phys. 2006, 95, 321-327.

14. Nishara, A.B.; Rajendran, V. Structure and elastic properties of $\mathrm{TeO}_{2}-\mathrm{BaF}_{2}$ glasses. J. Phys. Chem. Solids 2006, 67, 1697-1702.

15. Ibanez, A.; Ericsson, T.; Lindqvist, O.; Bazin, D.; Philippot, E. Local range order of tellurium atoms in $\mathrm{TeO}_{2}-\mathrm{BaO}$ and $\mathrm{TeO}_{2}-\mathrm{BaF}_{2}$ glassy systems. J. Mater. Chem. 1994, 4, 1101-1106.

16. Paul, A.; Roychoudhury, P.; Mukherjee, S.; Basu, C. Ultrasonic study of $(\mathrm{CuO})_{\mathrm{x}}(\mathrm{TeO})_{1-\mathrm{x}}$ glass system. J. Non-Cryst. Solids 2000, 275, 83-92.

17. Wang, G.; Zhang, J.; Dai, S.; Yang, J.; Jiang, Z. Thermal analyses, spectral characterization and structural interpretation of $\mathrm{Yb}^{3+}$ doped $\mathrm{TeO}_{2}-\mathrm{ZnO}^{3} \mathrm{ZnCl}_{2}$ glasses. Phys. Lett. A 2005, 341, 285-290.

18. Rajendran, V.; Palanivelu, N.; Chauduri, B.K.; Goswami, K. Characterisation of semiconducting $\mathrm{V}_{2} \mathrm{O}_{5}-\mathrm{Bi}_{2} \mathrm{O}_{3}-\mathrm{TeO}_{2}$ glasses through ultrasonic measurements. J. Non-Cryst. Solids 2003, 320, 195-209.

19. El-Adawy, A.; Moustafa, Y. Elastic properties of bismuth borate glasses. J. Phys. D Appl. Phys. 1999, 32, 2791-2796.

20. El-Mallawany, R. Theoretical and experimental IR spectra of binary rare earth tellurite glasses-1. Infrared Phys. 1989, 29, 781-785.

21. Al-Ani, S.K.J.; Higazy, A.A. Study of optical absorption edges in $\mathrm{MgO}-\mathrm{P}_{2} \mathrm{O}_{5}$ glasses. J. Mater. Sci. 1991, 26, 3670-3674.

22. Sidek, H.A.A.; Bahari, H.R.; Halimah, M.K.; Yunus, W.M.M. Preparation and elastic moduli of germanate glass containing lead and bismuth. Int. J. Mol. Sci. 2012, 13, 4632-4641.

23. Sidek, H.A.A.; Chow, S.P.; Talib, Z.A.; Halim, S.A. Formation and elastic behaviour of lead-magnesium chlorophosphate glasses. Turk. J. Phys. 2004, 28, 67-71.

24. Halimah, M.K.; Daud, W.M.; Sidek, H.A.A. Elastic properties of $\mathrm{TeO}_{2}-\mathrm{B}_{2} \mathrm{O}_{3}-\mathrm{Ag}_{2} \mathrm{O}$ glasses. Ionics 2010, 16, 807-813.

25. Halimah, M.K.; Sidek, H.A.A.; Daud, W.M.; Zainul, H.; Talib, Z.A.; Zaidan, A.W.; Zainal, A.S.; Mansor, H. Ultrasonic study and physical properties of borotellurite glasses. Am. J. Appl. Sci. 2005, 2, 1541-1546.

(C) 2012 by the authors; licensee MDPI, Basel, Switzerland. This article is an open access article distributed under the terms and conditions of the Creative Commons Attribution license (http://creativecommons.org/licenses/by/3.0/). 